\title{
МОДИФИЦИРУЮЩИЙ ЭФФЕКТ ПРОДУКТОВ ПЕРЕРАБОТКИ ОТХОДОВ НЕФТЕХИМИИ В ПРОЦЕССАХ СМАЧИВАНИЯ И СТАБИЛИЗАЦИИ ТВЕРДОФАЗНЫХ ЧАСТИЦ
}

\author{
Дюрягина Антонина Николаевна ${ }^{1}$, \\ adyuryagina@inbox.ru
}

\author{
Островной Кирилл Александрович1, \\ kostrovnoy@mail.ru
}

\author{
Козик Дарья Юрьевна 1 , \\ daria.kozik@mail.ru
1 Некоммерческое акционерное общество Северо-Казахстанский университет им. М. Козыбаева, Республика Казахстан, 150000, г. Петропавловск, ул. Пушкина, 86.

\begin{abstract}
Актуальность. Как свидетельствует опыт мировой практики, для лакокрасочных материалов на основе традиционных пленкообразующих требуется введение модифицирующих добавок различного фрункционального назначения, чтобы обеспечить оптимальные декоративные и защитные свойства. Отсутствие собственных производителей широкого спектра модифицирующих добавок приводит к необходимости их импорта из стран дальнего зарубежья, что значительно повышает себестоимость лакокрасочных материалов. Наличие огромных отходов нефртехимии (в крупнотоннажных масштабах) дает возможность производить дешевые, эфрфективные и конкурентоспособные модифицирующие добавки. Интеграция научнопроизводственных предприятий позволит повысить рентабельность производства лакокрасочной продукции, а также решить ряд вопросов, связанных с приготовлением, хранением и улучшением эксплуатационных характеристик покрытий. Стабильными считаются лакокрасочнье композиции, в которых осуществляется стабилизация пигментных дисперсий за счет формирования адсорбционно-сольватных слоев вокруг частиц пигмента из макромолекул пленкообразователя и добавляемых поверхностно-активных веществ. В связи с этим огромный практический интерес представляют дифрильные соединения, играющие роль поверхностно-активного вещества стабилизирующего действия

Цель: исследование смачивающего и стабилизирующего эфрфекта низкомолекулярного аминопроизводного AC-1, синтезированного из отходов нефотехимии (КОН-92), в составе лакокрасочных материалов.

Объекты: алкидно-уретановый лак «Уралкид», растворитель - уайт-спирит, пигмент - диоксид титана рутильной формы марки Р-02; в качестве модифицирующих добавок - аминосодержащие амфифильные вещества (АС, ПЭПА, ТЕЛАЗ).

Методы: пипеточный метод седиментационного анализа суспензий, метод адгезированного пузырька воздуха для измерения краевых углов смачивания.

Результаты. Установлен смачивающий и стабилизирующий эффрект синтезированного из нефтехимических отходов аминопроизводного AC, что позволяет при дозированном его расходе получать седиментационно-устойчивые композиции без расслоения и выпадения осадка. Доказано влияние пленкообразующего и поверхностно-активного вещества на процессы стабилизации дисперсии диоксида титана в алкидно-уретановых композициях.
\end{abstract}

\section{Ключевые слова:}

Отходы нефтехимии, лакокрасочные материалы, скорость седиментации,

краевой угол смачивания, диоксид титана, алкид-уретан, поверхностно-активное вещество.

\section{Введение}

В настоящее время защита объектов нефтегазовой отрасли, находящихся в эксплуатации, осуществляется в основном за счет применения лакокрасочных материалов (ЛКМ), отличающихся от других видов защиты доступностью, относительной дешевизной и простотой их использования. Как свидетельствует опыт мировой практики, качество ЛКМ обеспечивается максимальным диспергированием пигментов и стабилизацией мелких фракций в дисперсной системе путем подбора соответствующего пленкообразователя и добавки различных поверхностно-активных веществ (ПАВ) [1-3]. В отношении большого ряда пленкообразующих российские и казахстанские производители ЛКМ не уступают европейским, поскольку синтез пленкообразователей базировался на достижениях научной школы химии и технологии высокомолекулярных соединений, однако в применении модифицирующих добавок отставание экстремально. Наибольшее распространение получили поверхностно-активные модификаторы
«ТЕЛАЗ» ЗАО «АвТоконинвест», выпускаемые одним из немногих в России предприятий по производству модифицирующих добавок. Между тем [4], для красок на основе традиционных пленкообразующих требуется введение свыше 10 модифицирующих добавок различного функционального назначения, чтобы обеспечить оптимальные декоративные и защитные свойства. Как результат, при одном и том же пленкообразующем и пигменте качество ЛКМ уступает западным аналогам по реологическим свойствам, диспергированию и стабилизации дисперсной фазы, также по предотвращению расслоения краски. Причина такого явления заключается в том, что при отсутствии собственных производителей широкого спектра модифицирующих добавок в основном они закупаются из стран дальнего зарубежья, и это приводит к значительному повышению себестоимости ЛКМ. Между тем, при наличии огромных отходов нефтехимии (в крупнотоннажных масштабах) можно производить дешевые, эффективные и конкурентоспособные модифицирующие добав- 
ки. Интеграция научно-производственных предприятий позволит повысить рентабельность производства лакокрасочной продукции, а также решить ряд вопросов, связанных с приготовлением, хранением и улучшением эксплуатационных характеристик покрытий ЛКМ $[5,6]$.

При разработке наполненных лакокрасочных материалов необходимо обеспечить агрегативную и седиментационную устойчивость, что предотвращает образование плотного пигментного осадка при хранении эмали или краски. Пигментированные лакокрасочные материалы представляют собой высококонцентрированные дисперсии пигментов [7-9]. Пигментные дисперсии, как всякие коллоидные системы, имеют склонность к разрушению, при этом пигмент выпадает в осадок. Высокодисперсные системы могут быть устойчивы при условии сильных межмолекулярных взаимодействий между поверхностью пигмента и дисперсионной фазой композиции, в результате которых происходит максимальное понижение краевого угла смачивания жидкостью поверхности твердого тела $[10,11]$. Стабильными считаются лакокрасочные композиции, в которых осуществляется стабилизация пигментных дисперсий за счет формирования адсорбционно-сольватных слоев вокруг частиц пигмента из макромолекул пленкообразователя и добавляемых ПАВ [6-8]. В связи с этим огромный практический интерес представляют дифильные соединения, играющие роль ПАВ стабилизирующего действия $[12,13]$. При этом эффективность свойств
ПАВ определяется структурой и длиной углеводородного радикала, а также природой и содержанием полярных групп [14].

Для расширения ассортимента эффективных модифицирующих добавок представлялось целесообразным исследовать стабилизирующий эффект низкомолекулярного аминопроизводного АС, синтезированного из отходов нефтехимии (КОН-92), в сравнении с высокомолекулярными аминопроизводными ТЕЛАЗ и ПЭПА, которые изготавливаются промышленно. Это потребовало:

- изучения закономерностей развития процессов смачивания и седиментации дисперсий пигментированного диоксида титана в бинарных «растворитель-ПАВ» и тройных «растворительпленкообразующее-ПАВ» системах;

- оценки влияния концентрационных параметров и составов композиций на динамику осаждения частиц пигмента.

\section{Методы и материалы}

При проведении исследований использовали пленкообразующее - алкидно-уретановый лак «Уралкид» (ТУ 2311-023-45822449-2002), растворитель уайт-спирит (ТУ 2388-004-23172471-98) и пигмент диоксид титана рутильной формы марки Р-02 (ГОСТ 9804-84). В качестве модифицирующих добавок использовали аминосодержащие амфифильные вещества (табл. 1) [15-18].

Таблица 1. Характеристики исходных материалов

Table 1. Characteristics of raw materials

\begin{tabular}{|c|c|c|c|c|}
\hline $\begin{array}{l}\text { Название } \\
\text { Name }\end{array}$ & $\begin{array}{l}\text { Mr, a.e.m } \\
\text { Mr, a.m.u. }\end{array}$ & $\begin{array}{c}\text { Аминное число } \\
\text { (мг HCl/г) } \\
\text { Amine number } \\
\text { (mg HCl/g) }\end{array}$ & $\begin{array}{l}\text { Технические условия } \\
\text { Technical specifications }\end{array}$ & $\begin{array}{c}\text { Краткое описание } \\
\text { технического продукта } \\
\text { Brief description } \\
\text { of the technical product }\end{array}$ \\
\hline $\mathrm{AC} / \mathrm{AS}$ & 283 & 30 & 655-РК 056006434-002-2000 & $\begin{array}{l}\text { смесь первичных и вторичных аминов } \\
\text { mixture of primary and secondary amines }\end{array}$ \\
\hline $\begin{array}{l}\text { ПЭПА } \\
\text { РЕРА }\end{array}$ & 4950 & 31 & 2413-357-40203447-99 & $\begin{array}{c}\text { смесь высокомолекулярных аминов } \\
\text { mixture of high molecular weight amines }\end{array}$ \\
\hline $\begin{array}{l}\text { ТЕЛАЗ } \\
\text { TЕLAZ }\end{array}$ & 2121 & 32 & 2461-060-27991970-02 & $\begin{array}{l}\text { продукт конденсации растительных масел } \\
\text { с диаминами } \\
\text { condensation product of vegetable oils with diamines }\end{array}$ \\
\hline
\end{tabular}

\section{Методика проведения эксперимента}

Скорость седиментации и краевые углы смачивания измеряли в изотермических условиях (Т=293 К). В опытах варьировали массовое содержание алкидноуретанового лака $\left(\mathrm{C}_{\mathrm{yp}}\right)$ от 0 до $50 \%$ за счет разбавления уайт-спиритом уралкида, расходы ПАВ $\left(\mathrm{C}_{\text {ПАВ }}, \%\right.$ 0-4 на массу пигмента), время отбора суспензии $(\tau=10-28800 \mathrm{c})$. Для более полного смачивания порошка диоксида титана и стабилизации всех равновесных характеристик суспензию перемешивали 30 мин.

Методика приготовления растворов с различным содержанием пленкообразующего заключалась в предварительном разведении уайт-спиритом алкидноуретанового лака в следующих массовых соотношениях: $1: 9\left(\mathrm{C}_{\mathrm{yp}}=10 \%\right), 3: 7\left(\mathrm{C}_{\mathrm{yp}}=30 \%\right), 1: 1\left(\mathrm{C}_{\mathrm{yp}}=50 \%\right)$. Полученные растворы (в дальнейшем А) направляли на приготовление суспензий, которое осуществляли при температуре 293 К в герметичном реакторе (объемом 0,2 дм ${ }^{3}$, коэффициент заполнения - 0,60), снабженном перемешивающим устройством (импеллерная мешалка, частота - 300 мин $^{-1}$ ). Количественное содержание пигмента диоксида титана в растворе А задавали постоянным 3,86 г. Методика приготовления суспензий ЛКМ с различным содержанием аминопроизводных ( $\mathrm{C}_{\text {ПАв}}, \%, 0-4$ на массу пигмента) заключалась в добавлении определенной массы аминопроизводного в суспензию.

Влияние содержания пленкообразующего и расходов ПАВ на седиментационную устойчивость суспензий диоксида титана определяли пипеточным методом, сущность которого заключалась в отборе строго определенного объема оседающей суспензии через различные промежутки времени на высоте $h$ и нахождении массы твердофазных частиц в отобранной пробе. 
Пробирку с суспензией закрепляли в неподвижный штатив, и через установленные промежутки времени отбирали 1,5 мл суспензии, опуская пипетку на глубину $2 / 3$ пробирки. Пробу помещали в фарфоровую чашку, доведенную до постоянной массы и выпаривали до полного испарения легколетучего растворителя. Остатки нелетучей органической части суспензии сжигали в муфельной печи при $600{ }^{\circ} \mathrm{C}$. Далее находили массу пигмента с точностью до 0,001 г.

На основании полученных данных были построены типичные кинетические зависимости седиментации (рис. 1). На зависимости седиментационного осаждения частиц пигмента изучаемых систем можно выделить два участка: первый участок - последовательное осаждение частиц пигмента $\mathrm{TiO}_{2}$; второй выход кривых на насыщение к моменту завершения процесса осаждения.

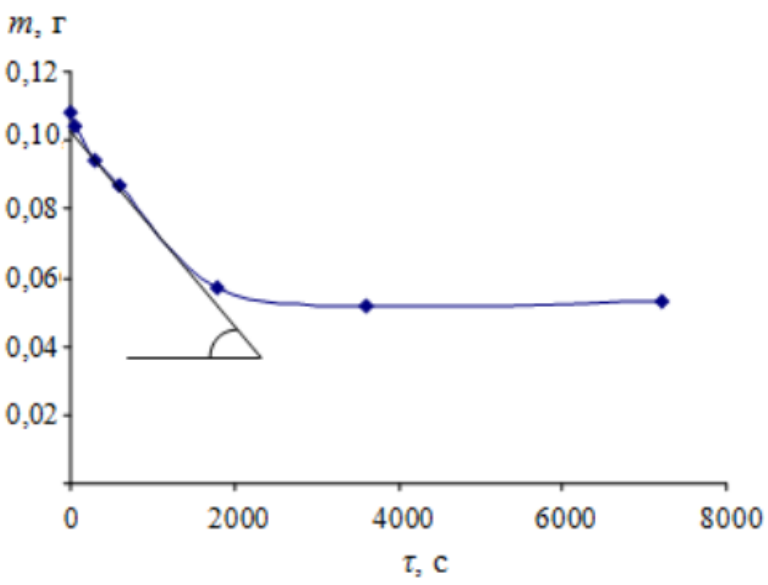

Pис. 1. Типичная зависимость массы пигмента от времени его осаждения: концентрация пленкообразуюшего $10 \%$

Fig. 1. Typical dependence of the pigment mass on the time of its deposition: concentration of the film-forming agent $10 \%$

Динамика осаждения частиц пигмента характеризуется скоростью седиментации, которую находили графически. Для этого к первому прямолинейному участку проводили касательную и рассчитывали тангенс угла наклона. Скорость (г/с) определяли по уравнению $V=\operatorname{tg} \alpha$.

Измерение краевых углов смачивания $(\theta)$ модифицированными суспензиями поверхности диоксида титана осуществляли изотермически ( $T=293 \mathrm{~K})$ по методу адгезированного пузырька воздуха. Качество поверхности диоксида титана оценивали по параметру шероховатости $(\mathrm{Rz})$ с применением компьютерномикрооптического метода (на базе микроскопа МИС11) [19]. Образцы диоксида титана с параметром шероховатости $(\mathrm{Rz})$ свыше 0,8-1,0 мкм отбраковывали. Методика эксперимента [20] была разработана так, чтобы получить изображение пузырька воздуха, подведенного под нижнюю поверхность диоксида титана, погруженного (на незначительную глубину) в исследуемую суспензию. По контуру зафиксированного его изображения (в области контакта с поверхностью $\mathrm{TiO}_{2}$ ) определяли высоту $h$ и диаметр пузырька $d$.
Краевой угол смачивания между твердой поверхностью и касательной к точке соприкосновения трех фаз рассчитывали, усредняя результаты трех параллельных измерений, по формуле (1):

$$
\theta=180^{\circ}-\theta,
$$

$\theta$ ' рассчитывали через $\cos \theta$ '

$$
\cos \theta=\frac{(d / 2)^{2}-h^{2}}{(d / 2)^{2}+h^{2}} .
$$

\section{Результаты и их обсуждение}

На первом этапе были проведены исследования влияния ПАВ на скорость осаждения частиц $\mathrm{TiO}_{2}$ в растворителе, что исключает возможное влияние пленкообразующего на седиментационные процессы. Эффект трех разновидностей аминопроизводных в уайт-спирите на скорость седиментации характеризуют зависимости, представленные на рис. 2, кривые 1-3.

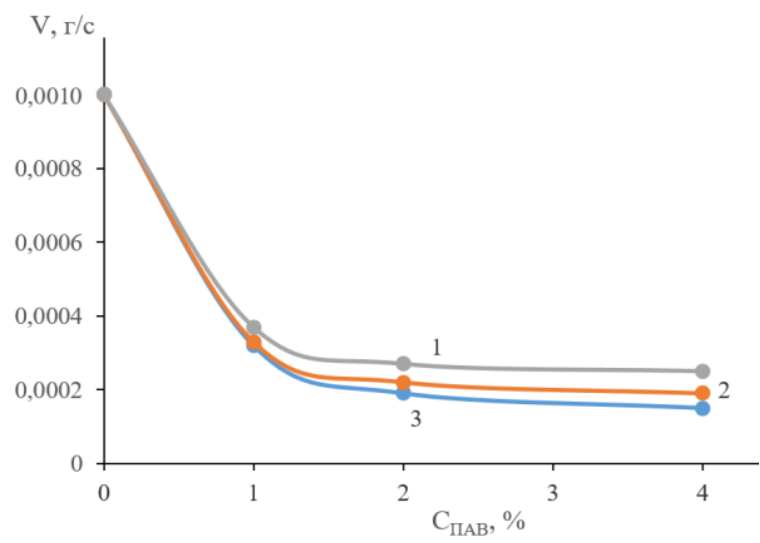

Pис. 2. Зависимость скорости седиментации от концентрации ПАВ: 1 - АС, 2 - ПЭПА, 3 - ТЕЛАЗ

Fig. 2. Sedimentation rate dependence on the surfactant concentration: $1-A S, 2-P E P A, 3-T E L A Z$

Введение ПАВ сопровождается существенными изменениями в кинетике осаждения частиц пигмента. По мере увеличения концентрации ПАВ $\left(\mathrm{C}_{\text {ПАВ }} \leq 1 \%\right)$ в суспензиях, не содержащих пленкообразующее, скорость седиментации замедляется в 3,1-3,7 раза (в сравнении с базовым вариантом - без ПАВ). За пределами этого концентрационного участка $\left(\mathrm{C}_{\text {ПАВ }}>1 \%\right)$ процессы стабилизации суспензий получают дальнейшее развитие, но с различной интенсивностью. Наблюдаемые различия в развитии процессов седиментации определяются молекулярно-массовым составом и одновременно структурой трех разновидностей аминопроизводных, которые отвечают за создание защитного адсорбционно-сольватного слоя на поверхности частиц пигмента. В изоконцентрационных по содержанию ПАВ суспензиях наибольшим эффектом обладают более высокомолекулярные разновидности ПЭПА, ТЕЛАЗ (рис. 2, кривые 2, 3) в сравнении с низкомолекулярным аминопроизводным $\mathrm{AC}$ (рис. 2, кривая 1). Так, в суспензиях низкомолеку- 
лярного $\mathrm{AC}$ по мере повышения его содержания до 4 \% скорость осаждения частиц пигмента стабилизировалась на минимальном уровне $-0,31 \cdot 10^{-3}$ г/с, что в 3,8 раза меньше, чем в суспензии без ПАВ. В присутствии же высокомолекулярных аминопроизводных суспензии становились напротив все более седиментационно устойчивыми; скорость седиментации $\mathrm{TiO}_{2}$ снизилась вплоть до значений $0,15 \cdot 10^{-3}$ и $0,10 \cdot 10^{-3}$ г/с в суспензиях с ПЭПА и ТЕЛАЗ, то есть в 6,6 и 9,8 раза соответственно.

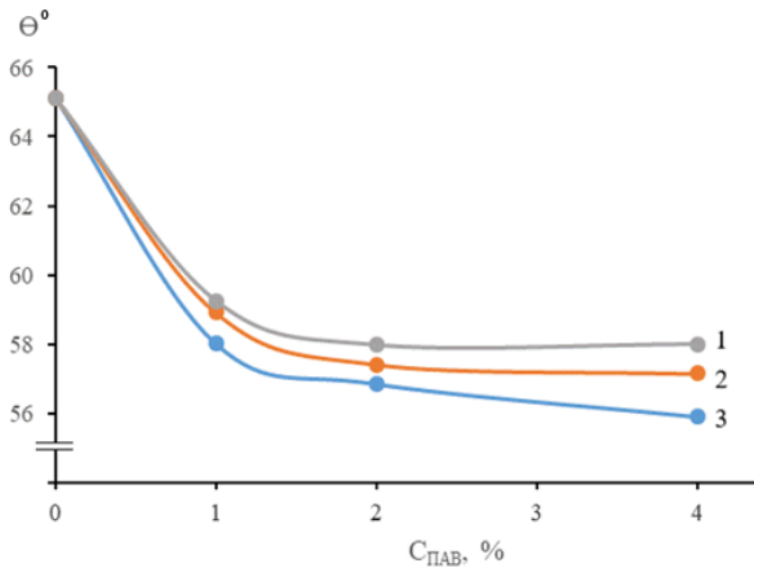

Pис. 3. Изотермы (T=293 К) краевых углов смачивания диоксида титана: 1 - АС, 2 - ПЭПА, 3 - ТЕЛАЗ

Fig. 3. Isotherms $(T=293 \mathrm{~K})$ of the edge angles of wetting of titanium dioxide: 1 -AS, 2 - PEPA, 3 - TELAZ
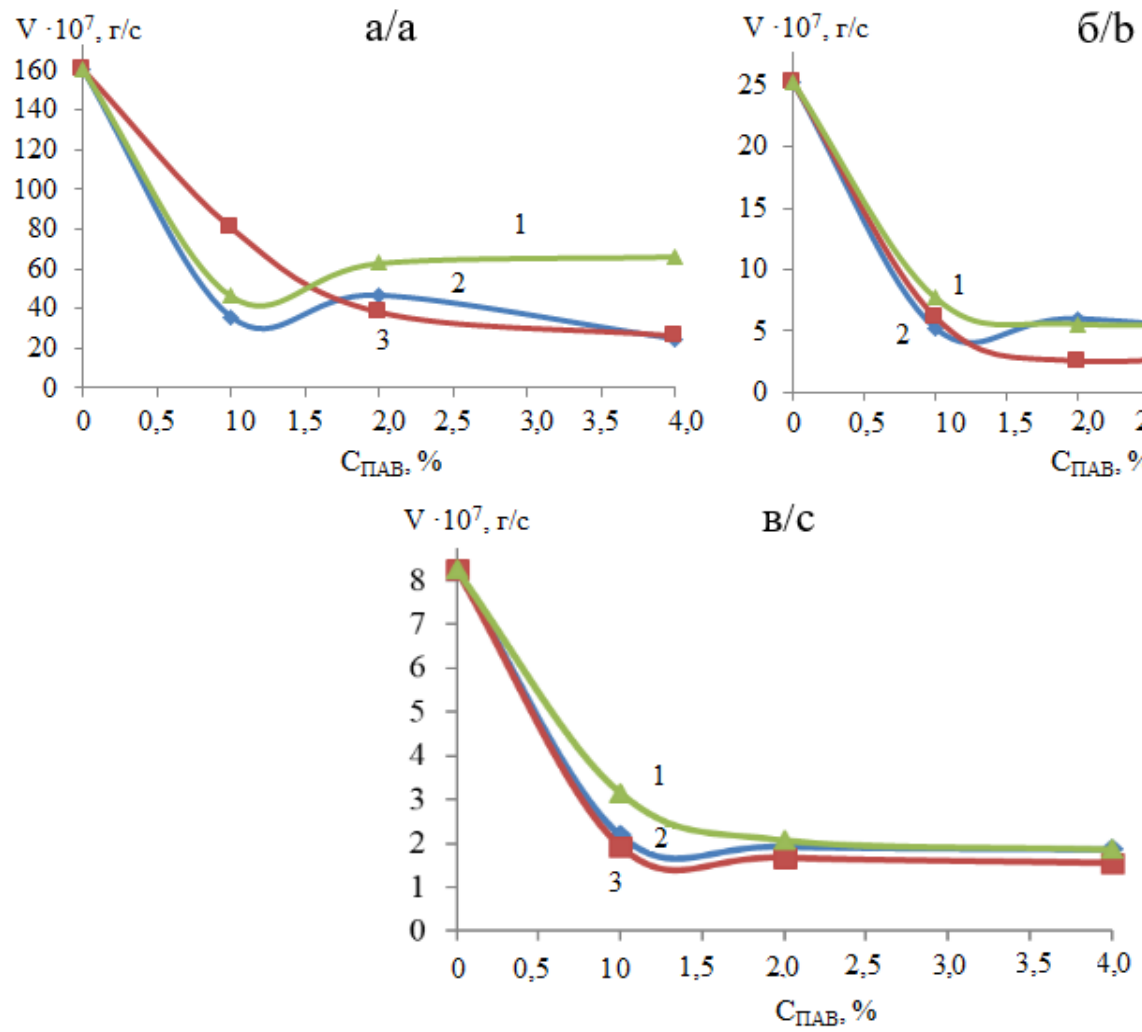

Рис. 4. Влияние содержания пленкообразующего и концентрации ПАВ на скорость седиментации: концентраџия пленкообразующего: а) $10 \%$; б) $30 \%$; в) $50 \% .1$ - АС, 2 - ПЭПА, 3-ТЕЛАЗ

Fig. 4. Effect of the film-forming agent content and the concentration of surfactants on the sedimentation rate: concentration of the film-forming agent: a) $10 \%$; b) $30 \%$; c) $50 \%$. 1-AS, 2-PEPA, 3 -TELAZ

Улучшение седиментационной устойчивости объясняется глубокой лиофилизацией поверхности диоксида титана, которую наглядно демонстрирует уменьшение краевых углов смачивания $\theta$ в растворах ПАВ (рис. 3, кривые 1-3). При этом прослеживается тесная корреляция между этими двумя зависимостями (рис. 2, 3).

Равностепенный смачивающий эффект всех аминосодержащих растворов в той же области малых концентраций $(\mathrm{c} \leq 1 \%)$; угол $\theta$ уменьшается на $6-7^{\circ}$ в сравнении с уайт-спиритом $\left(\theta=65^{\circ}\right)$. За пределами этого концентрационного участка (c>1\%) аминопроизводные в порядке увеличения смачивающей активности в отношении диоксида титана образуют ряд: ТЕЛАЗ $>$ ПЭПА $>$ АС

Таким образом, по результатам проведенных исследований можно заключить, что все разновидности аминопроизводных обладают смачивающим и стабилизирующим действиями. Максимальный эффект $(\min V$ и $\min \theta)$ достигается в случае использования ТЕЛАЗ при его содержании в суспензии 4 \% (рис. 2, кривая 3 и рис. 3 , кривая 3 ).

На втором этапе были проведены исследования влияния ПАВ на скорость осаждения частиц $\mathrm{TiO}_{2}$ в суспензиях с различным содержанием пленкообразующего в растворителе. Влияние природы и количественных содержаний аддитивов на седиментационную устойчивость дисперсий диоксида титана в алкидно-уретановых суспензия $\left(\mathrm{C}_{\mathrm{yp}}=10-50 \%\right)$ отражают зависимости на рис. 4.

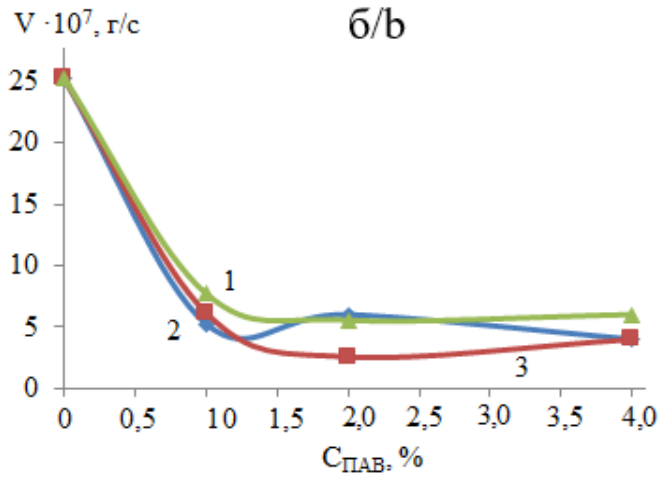


Анализ полученных результатов показывает, что при отсутствии ПАВ $\left(\mathrm{C}_{П}=0 \%\right)$ скорость седиментации суспензий диоксида титана зависит от содержания в них пленкообразующего. В сравнении с показателем седиментации $\mathrm{TiO}_{2}$ в уайт-спирите $\left(\mathrm{C}_{\text {пл }}=0 \%\right)$ скорость осаждения твердофазных частиц уменьшается в суспензии $\left(\mathrm{C}_{\text {плл }}=10 \%\right)$ в 60 раз и составляет $160,42 \cdot 10^{-7} \mathrm{\Gamma} / \mathrm{c}$.
Судя по резкому снижению скорости седиментации при введении $10 \%$ уралкида в растворитель (рис. 4, a) произошло блокирование части поверхности диоксида титана макромолекулами пленкообразующего. Об этом свидетельствует уменьшение значения $\theta$ не менее чем на $12^{\circ}\left(\theta=52,70^{\circ}\right)$ при увеличении концентрации пленкообразующего от 0 до 10 \% (табл. 2).

Таблица 2. Экспериментальные значения краевых углов смачивания

Table 2. Experimental values of the wetting edge angles

\begin{tabular}{|c|c|c|c|c|c|c|}
\hline \multirow{3}{*}{$\begin{array}{l}\text { Концентрация ПАВ, \% } \\
\text { Surfactant concentration, \% }\end{array}$} & ТЕЛАЗ/TELAZ & ПЭПА/РЕРА & $\mathrm{AC} / \mathrm{AS}$ & ТЕЛАЗ/TELAZ & ПЭПА/РЕРА & $\mathrm{AC} / \mathrm{AS}$ \\
\hline & \multicolumn{6}{|c|}{ Концентрация пленкообразующего/Film-forming agent concentration } \\
\hline & \multicolumn{3}{|c|}{$0 \%$} & \multicolumn{3}{|c|}{$10 \%$} \\
\hline 0 & 65,13 & 65,13 & 65,13 & 52,70 & 52,70 & 52,70 \\
\hline 1 & 58,02 & 58,92 & 59,26 & 48,28 & 49,28 & 49,62 \\
\hline 2 & 57,79 & 57,88 & 57,88 & 47,37 & 48,59 & 48,13 \\
\hline 3 & 56,85 & 58,15 & 57,05 & 46,46 & 47,72 & 47,56 \\
\hline \multirow[t]{3}{*}{4} & 55,35 & 57,14 & 57,26 & 45,17 & 46,60 & 44,14 \\
\hline & \multicolumn{6}{|c|}{ Концентрация пленкообразующего/Film-forming agent concentration } \\
\hline & \multicolumn{3}{|c|}{$30 \%$} & \multicolumn{3}{|c|}{$50 \%$} \\
\hline 0 & 46,46 & 46,46 & 46,46 & 44,73 & 44,73 & 44,73 \\
\hline 1 & 44,42 & 45,72 & 44,71 & 42,97 & 43,30 & 43,81 \\
\hline 2 & 45,31 & 44,84 & 44,16 & 40,90 & 41,31 & 41,24 \\
\hline 3 & 43,49 & 44,59 & 41,46 & 38,80 & 39,00 & 38,46 \\
\hline 4 & 42,29 & 43,21 & 38,15 & 36,32 & 36,88 & 36,75 \\
\hline
\end{tabular}

Однако при дальнейшем повышении содержания уралкида наблюдается тенденция к снижению темпов стабилизации. Увеличение концентрации пленкообразующего на 20 \% (от 10 до 30 \%) уменьшает скорость седиментации только в 6,4 раза $\left(\mathrm{V}=25,21 \cdot 10^{-7} \mathrm{\Gamma} / \mathrm{c}\right)$, что в 10 раз меньше эффекта, наблюдаемого при введении $10 \%$ уралкида (рис. 4,6 ). В сравнении с суспензией $\left(\mathrm{C}_{\text {пл}}=10 \%\right)$ краевой угол смачивания снижается на $7,97^{\circ}$ и составляет $46,46^{\circ}$ (табл. 2). При последующем увеличении содержания пленкообразующего на $20 \%$ (от 30 до $50 \%$ ) фиксировали (рис. 4, в) еще меньшее снижение (в 3 раза) скорости осаждения твердофазных частиц $\left(\mathrm{V}_{\text {сед }}=8,25 \cdot 10^{-7} \mathrm{\Gamma} / \mathrm{c}\right)$. Очевидно, что эффект олеофилизации и, как следствие, стабилизации твердофазных дисперсий пигмента в немодифицированных суспензиях ограничивает процесс ассоциации макромолекул, который усиливается по меpe увеличения концентрации пленкообразующего. Это указывает на ограниченное число сегментов асоциатов, закрепленных на твердой поверхности $\mathrm{TiO}_{2}$ В результате этого интенсивность процессов олеофилизации постепенно ослабевает, и при переходе концентрации пленкообразующего от 30 к 50 \% значение краевого угла смачивания $\theta$ (табл. 2) меняются незначительно $\left(\Delta \theta=1,75^{\circ}\right)$.

Введение аминосодержащих ПАВ в алкидноуретановые суспензии открывает дополнительные возможности к снижению скорости седиментации (рис. 4).

Как свидетельствуют экспериментальные данные, максимум стабилизирующей активности ПАВ в алкидно-уретановых суспензиях находится в той же области концентраций аддитивов $\left(\mathrm{C}_{\text {ПАВ }}=4 \%\right)$, что и в суспензиях $\mathrm{TiO}_{2}$ в уайт-спирите. Наибольший стабилизирующий эффект в суспензиях с 10 и 30 \% алкид-уретана был достигнут при введении ПЭПА и ТЕЛАЗ. При дозировании 4 \% высокомолекулярных ПЭПА и ТЕЛАЗ в такие суспензии фиксировали равностепенные (по скорости седиментации) характеристики стабилизации, которые составили $(24,56 \ldots 26,66) \cdot 10^{-7} \quad$ г/с при $\mathrm{C}_{\text {плл }}=10 \%$ и $(3,98 \ldots 4,03) \cdot 10^{-7} \quad$ г/с при $\mathrm{C}_{\text {плл }}=30 \%$. В суспензиях $\left(\mathrm{C}_{\text {пл }}=10-30 \%\right)$ с низкомолекулярным АС эффект стабилизации при той же концентрации $\left(\mathrm{C}_{\text {ПАВ }}=4 \%\right)$ был ниже: значения скорости седиментации уменьшились до $66,13 \cdot 10^{-7}$ г/с при $\mathrm{C}_{\text {пл}}=10 \%$ и до 5,99.10 $10^{-7}$ г/с при $\mathrm{C}_{\text {пл }}=30 \%$.

Таким образом, по усилению стабилизирующего эффекта в отношении дисперсий диоксида титана в изоконцентрационных по содержанию ПАВ $\left(\mathrm{C}_{\text {ПАВ }}=4 \%\right)$ алкид-уретановых суспензиях $\left(\mathrm{C}_{\text {пл }}=10-30 \%\right)$ модификаторы образуют ряд: ПЭПА=ТЕЛАЗ $>$ АС.

Однако при дальнейшем повышении концентрации пленкообразующего в суспензии $\left(\mathrm{C}_{\text {пл }}=50\right.$ \%) данная последовательность нарушается и имеет вид: ПЭПА=АС $\approx$ ТЕЛАЗ. Значения скорости седиментации твердофазных частиц в изоконцентрационных по содержанию ПАВ суспензиях уменьшились до близких значений и составили $1,87 \cdot 10^{-7}$ г/с (ПЭПА, АС) и $1,75 \cdot 10^{-7}$ г/с (ТЕЛАЗ).

Причину изменений влияния ПАВ на устойчивость суспензий по мере увеличения концентрации пленкообразующего позволяет понять сопоставительный анализ относительных изменений скорости седиментации. Относительные изменения скорости седиментации $\left(V_{\text {отн }}\right)$ рассчитывали по формуле (3):

$$
V_{\text {отн }}=\frac{V_{f=0}}{V_{f}},
$$

где $V_{f=0}-$ скорость на нулевом уровне варьируемых факторов; $V_{f}$ - скорости седиментации при вариациях концентрации ПАВ и пленкообразующего.

Рассчитанные значения относительного изменения скорости седиментации в зависимости от содержания пленкообразующего и концентрации ПАВ представлены в табл. 3. 
Таблица 3. Относительные изменения скорости осаждения диоксида титана в суспензиях

Table 3. $\quad$ Relative changes in the deposition rate of titanium dioxide in suspensions

\begin{tabular}{|c|c|c|c|c|c|c|c|c|c|c|c|c|}
\hline \multirow{3}{*}{$\begin{array}{c}\text { Концентрация ПАВ } \\
\text { Surfactant concentration, \% }\end{array}$} & \multicolumn{4}{|c|}{ ПЭПА/РЕРА } & \multicolumn{4}{|c|}{ ТЕЛАЗ/TЕLAZ } & \multicolumn{4}{|c|}{$\mathrm{AC} / \mathrm{AS}$} \\
\hline & \multicolumn{12}{|c|}{ Концентрация пленкообразующего/Film-forming agent concentration, \% } \\
\hline & 0 & 10 & 30 & 50 & 0 & 10 & 30 & 50 & 0 & 10 & 30 & 50 \\
\hline 1 & 3,7 & 4,5 & 4,8 & 3,8 & 3,5 & 2,0 & 4,1 & 4,3 & 3,1 & 3,5 & 3,3 & 2,6 \\
\hline 2 & 5,0 & 3,4 & 4,2 & 4,3 & 6,7 & 4,2 & 9,9 & 4,9 & 3,6 & 2,6 & 4,6 & 4,0 \\
\hline 4 & 6,6 & 6,5 & 6,3 & 4,4 & 9,8 & 6,0 & 6,3 & 4,7 & 3,8 & 4,1 & 4,2 & 4,4 \\
\hline
\end{tabular}

Сопоставительный анализ показал, что введение пленкообразующего практически не повлияло на вклад АС в изменение седиментационной устойчивости суспензий. В алкид-уретановых суспензиях $\mathrm{TiO}_{2}$ при любом содержании пленкообразующего в уайтспирите $\mathrm{AC}\left(\mathrm{C}_{П \mathrm{AB}}=4 \%\right)$ уменьшает скорость седиментации в 4,1...4,4 раза, то есть на том же уровне, что и в суспензиях растворителя. Это указывает на отсутствие конкурентной адсорбции между полимером и вводимым ПАВ, то есть АС сорбируется на активных участках поверхности пигмента, свободных от макромолекул пленкообразующего. Учитывая возможные кислотно-основные взаимодействия, концентрирование органического аминопроизводного АС происходит на кислотных центрах.

Однако для ПЭПА глубина изменения седиментационной устойчивости (в 6,3...6,6 раза) суспензий под его влиянием $\left(\mathrm{C}_{\text {ПАВ }}=4 \%\right)$ остается неизменной только при увеличении содержания пленкообразующего от 0 до $30 \%$ в суспензиях диоксида титана. Дальнейшее концентрирование алкид-уретана $\left(\mathrm{C}_{\text {пл }}=50 \%\right)$ сопровождалось снижением относительного изменения скорости седиментации от 6,3 до 4,4, то есть до значения равнозначного с АC (табл. 3 ).

Другая разновидность высокомолекулярного органического аминопроизводного ТЕЛАЗ, в отличие от ПЭПА, снижает свой стабилизирующий эффект в 1,6 раза (от 9,8 до 6,0...6,3) уже при $\mathrm{C}_{п л}=10-30 \%$. Снижение его глубины (от 6,3 до 4,7) получает дальнейшее развитие при $\mathrm{C}_{\text {пл }}=50 \%$, и в результате стабилизирующий эффект ТЕЛАЗ становится близким к эффекту АС

Таким образом, экспериментально установленные закономерности устойчивости тройных систем «пигмент-пленкообразующее-ПАВ» наглядно демонстрируют влияние длины и структуры углеводородного радикала ПАВ на процессы смачивания и стабилизации. В концентрированных по содержанию пленкообразующего суспензиях образование плотного адсорбционно-сольватного слоя на поверхности диоксида титана ограничивает движение молекул ПАВ с длинными углеводородными радикалами (ТЕЛАЗ и ПЭПА) и препятствует их адсорбции на свободных кислотных центрах $\mathrm{TiO}_{2}$. Как следствие, смачивающий эффект ПЭПА и ТЕЛАЗ в таких суспензиях $\left(\mathrm{C}_{\text {пл }}=50 \%\right)$ на $20 \%$ ниже, чем в суспензиях $\mathrm{TiO}_{2}$ в растворителе. Краевые углы смачивания в присутствии $\left(\mathrm{C}_{\text {ПАВ }}=4 \%\right)$ ПЭПА и ТЕЛАЗ уменьшились на

\section{СПИСОК ЛИТЕРАТУРЫ}

1. Кирбятьева Т.В. Атмосферостойкие лакокрасочные покрытия для защиты от коррозии технологического оборудования и металлоконструкций // Лакокрасочные материалы и их применение. - 2001. - № 1. - С. 30-35.
7-8 по сравнению с немодифицированной суспензией $\left(\mathrm{C}_{\text {пл }}=50 \%\right)$ и составили $36-37^{\circ}$ (табл. 2).

При этих же условиях АС с коротким углеводородным радикалом легко проникает сквозь полости ассоциатов макромолекул пленкообразующего и адсорбируется на кислотных центрах $\mathrm{TiO}_{2}$. Как результат, смачивающий эффект $\mathrm{AC}$ остается на том же уровне (табл. 2), что и в суспензиях $\mathrm{TiO}_{2}$ без пленкообразующего $\left(\Delta \theta=7,98^{\circ}\right)$.

Выравнивание смачивающего эффекта всех трех ПАВ, обусловленного стерическими препятствиями для длинных углеводородных радикалов высокомолекулярных аминопроизводных, по мере заполнения пигмента пленкообразующим приводит, в конечном счете, к равному снижению скорости седиментации модифицированных суспензий. Надежная стабилизация модифицированных суспензий достигается за счет формирования межфазного адсорбционносольватного барьера, толщина которого превышает зону притяжения частиц.

\section{Выводы}

1. Эффект стабилизации дисперсии диоксида титана в алкидно-уретановых композициях является аддитивной величиной, определяемой вкладом пленкообразующего и поверхностно-активного вещества.

2. Процессы седиментации лимитируются процессом смачивания, который, в свою очередь, изменяется в зависимости от концентрации и особенностей состава аминопроизводных (длины и структуры углеводородного радикала).

3. АС является эффективным смачивающим и стабилизирующим поверхностно-активным веществом, что позволяет при дозированном его расходе получать седиментационно-устойчивые композиции без расслоения и выпадения осадка.

4. В рабочих рецептурах лакокрасочных материалов на основе алкид-уретанового пленкообразующего $\left(\mathrm{C}_{\text {пл }}=50 \%\right)$ рекомендуется введение $4 \% \mathrm{AC}$, которое обеспечивает снижение скорости седиментации в 4,4 раза $\left(\mathrm{V}_{\text {сед }}=1,87 \cdot 10^{-7} \Gamma / \mathrm{c}\right)$. При введении такого же количества ПЭПА и ТЕЛАЗ достигается равный эффект.

Работа выполнена при финансовой поддержке МОН РК (грант № AP08856284).

2. Transferral of HMs pollution from road-deposited sediments to stormwater runof during transport processes / Q. Wang, Q. Zhang, M. Dzakpasu, N. Chang, X. Wang // Frontiers of Environmental Science and Engineering. - 2019. - V. 13. - P. 193-198. 
3. Хохлачева Н.М. Коррозия металлов и средства защиты от коррозии. - М.: Изд-во ИНФРА-М, 2016. - 118 с.

4. Толстая С.Н. Физико-химические основы адсорбционной активации минеральных наполнителей и пигментов в полимерных системах: автореф. дис. ... д-ра хим. наук. - М., 1970. $34 \mathrm{c}$.

5. Snow-dirt sludge as an indicator of environmental and sedimentation processes in the urban environment / A. Seleznev, I. Yarmoshenko, G. Malinovsky, E. Ilgasheva, E. Baglaeva, A. Ryanskaya, D. Kiseleva, T. Gulyaeva // Scientific Reports. 2019. - V. 9. - P. 1-12.

6. Опанасенко О.Н., Яковец Н.В., Крутько Н.П. Флокуляция и седиментация нефтяных дисперсных систем в присутствии добавок, содержащих амино- и фосфатные группы // Известия Национальной академии наук Беларуси. Серия химических наук. - 2017. - № 1. - С. 99-108.

7. Нефедов Н.И., Семенова Л.В., Кузнецова В.А., Веренинова Н.П. Лакокрасочные покрытия для защиты металлических и полимерных композиционных материалов от старения, коррозии и биоповреждения // Авиационные материалы и технологии. 2019. - № 5. - C. 393-404.

8. Iron nanoparticles-based magnetorheological fluids: a balance between MR effect and sedimentation stability / W. Zhu, X. Dong, H. Huang, M. Qi // Journal of Magnetism and Magnetic Materials. - 2019. - V. 491. - P. 165556.

9. Сумм Б.Д., Горюнов Ю.В. Физико-химические основы смачивания и растекания. - М.: Химия, 1976. -232 с.

10. Толстая С.Н., Шабанова С.А. Применение поверхностноактивных веществ в лакокрасочной промышленности. - М.: Химия, 1979. - $176 \mathrm{c}$.

11. Davis R.H., Birdsel J. Hindered settling of semidilute monodisperse and polydisperse suspensions // The AIChE Journal. - 1988. - V. 34. - № 1. - P. 123-129.

12. Procalcitonin, C-reactive protein, and erythrocyte sedimentation rate for the diagnosis of acute pyelonephritis in children /
K.J. Shaikh, V.A. Osio, M.M. Leeflang, N. Shaikh // Cochrane Database of Systematic Reviews. - 2015. - V. 1. - P. CD009185.

13. Patwardhan V.S., Chi Tien Sedimentation and liquid fluidization of solid particles of different sizes and densities // Chemical Engineering Science. - 1985 - V. 40. - P. 1051-1060.

14. Sedimentation of nanoplastics from water with $\mathrm{Ca} / \mathrm{Al}$ dual flocculants: characterization, interface reaction, effects of $\mathrm{pH}$ and ion ratios / Z. Chen, J. Liu, C. Chen, Z. Huang // Chemosphere. 2020. - V. 252. - P. 126450

15. Способ получения ингибитора кислотной коррозии металлов. пат. РК №22296, заявл. 11.07.2008; опубл. 15.02.2010. Бюл № 2. -5 c.

16. Barfod N. Concentration dependence of sedimentation rate of particles in dilute suspensions // Powder Technology Journal. 1972. - № 6 - P. 39-43.

17. Passowa U., Stout S.A. Character and sedimentation of «lingering» Macondo oil to the deep-sea after the Deepwater Horizon oil spill // Marine Chemistry. - 2020. - V. 218. P. 10373310.

18. Dyuryagina A.N. Modification of composites by surfactants. Petropavlovsk: NKZU, 2020. $-183 \mathrm{p}$

19. Компьютерно-микрооптический комплекс для качественноколичественной оценки качества поверхности изделий. Свидетельство № 0806РК0079, заявл. 06.07.2006. - 41 с.

20. Особенности влияния синтезированного модификатора $\mathrm{AC}$ на регулирование межфазных процессов в системе «пигментрастворитель» / А.Н. Дюрягина, Ю.С. Бызова, К.А. Островной, А.А. Кондратов, А.М. Лукманова // Актуальные проблемы науки и образования в области естественных и сельскохозяйственных наук: Материалы II Международной научно-практической конференции. - Петропавловск: Северо-Казахстанский государственный университет, 2014. - С. 142-147.

Поступила 01.12.2021 2.

\section{Информация об авторах}

Дюрягина А.Н., профессор кафедры химии и химических технологий, Некоммерческое акционерное общество Северо-Казахстанский университет им. М. Козыбаева.

Островной К.A., старший преподаватель кафедры химии и химических технологий, Некоммерческое акционерное общество Северо-Казахстанский университет им. М. Козыбаева.

Козик Д.Ю., студент кафедры химии и химических технологий, Некоммерческое акционерное общество Северо-Казахстанский университет им. М. Козыбаева. 
UDC 541.183

\title{
MODIFYING EFFECT OF PETROCHEMICAL WASTE PROCESSING PRODUCTS ON WETTING AND STABILIZATION OF SOLID-PHASE PARTICLES
}

\author{
Antonina N. Dyuryagina1, \\ adyuryagina@inbox.ru \\ Kirill A. Ostrovnoy 1 , \\ kostrovnoy@mail.ru \\ Daria Yu. Kozik', \\ daria.kozik@mail.ru \\ ${ }^{1}$ NC JSC North Kazakhstan University named after M. Kozybayev, \\ 86, Pushkin street, Petropavlovsk, 150000, Kazakhstan.
}

Relevance. As evidenced by the experience of the world practice, for paint and varnish materials based on traditional film-forming materials, the introduction of modifying additives of various functional purposes is required to ensure optimal decorative and protective properties. The lack of own manufacturers of a wide range of modifying additives leads to the need to import them from foreign countries, which significantly increases the cost of paint and varnish products. The presence of huge petrochemical waste (on a large scale) makes it possible to produce cheap, effective and competitive modifying additives. The integration of research and production enterprises will increase the profitability of the production of paint and varnish products, as well as solve a number of issues related to the preparation, storage and improvement of the performance characteristics of paint and varnish coatings. Paint and varnish compositions are considered stable, the stabilization of pigment dispersions is carried out due to the formation of adsorption-solvate layers around the pigment particles from the filmforming macromolecules and the added surfactants. In this regard, diphilic compounds that play the role of surfactants with a stabilizing effect are of great practical interest

The main aim of the research is to study the wetting and stabilizing effect of the low-molecular-weight amino derivative AC-1, synthesized from petrochemical waste (CRP-92), in the composition of paint coatings

Methods: pipette method of sedimentation analysis of suspensions, the method of the adhered air bubble for measuring the edge angles of wetting.

Result. The wetting and stabilizing effect of the amine-derived AC synthesized from petrochemical waste has been established, which makes it possible to obtain sedimentation-resistant compositions without stratification and precipitation at its dosed consumption. The effect of the film-forming agent and surfactant on stabilization of the titanium dioxide dispersion in alkyd-urethane compositions was proved.

\section{Key words:}

Petrochemical waste, paint and varnish materials, sedimentation rate, wetting edge angle, titanium dioxide, urethane alkyd, surfactant.

The research was financially supported by the MES RK (grant no. AP08856284).

\section{REFERENCES}

1. Kirbyateva T.V. Atmosferostoykie lakokrasochnye pokrytiya dlya zashchity ot korrozii tekhnologicheskogo oborudovaniya i metallokonstruktsy [Weather-resistant paint and varnish coatings for corrosion protection of technological equipment and metal structures]. Lakokrasochnye materialy $i$ ikh primenenie, 2001, no. 1, pp. 30-35.

2. Wang Q., Zhang Q., Dzakpasu M., Chang N., Wang X. Transferral of HMs pollution from road-deposited sediments to stormwater runof during transport processes. Frontiers of Environmental Science and Engineering, 2019, vol. 13, pp. 193-198.

3. Khokhlacheva N.M. Korrosia metallov $i$ sredstva zashchity ot kor rosii [Corrosion of metals and means of corrosion protection]. Moscow, INFRA-M Publ., 2016. 118 p.

4. Tolstaya S.N. Fisiko-khimicheskie osnovy adsorbtsionnoy activatsii mineralnykh napolniteley i pigmentov $v$ polimernykh sistemakh. Avtoreferat Dis. Kand. nauk [Physico-chemical bases of adsorption activation of mineral fillers and pigments in polymer systems. Cand. Diss. Abstract]. Moscow, 1970. 34 p.

5. Seleznev A., Yarmoshenko I., Malinovsky G., Ilgasheva E., Baglaeva E., Ryanskaya A., Kiseleva D., Gulyaeva T. Snow-dirt sludge as an indicator of environmental and sedimentation processes in the urban environment. Scientific Reports, 2019, vol. 9, pp. 17241.

6. Opanasenko O.N., Yakovets N.V., Krutko N.P. Flocculation and sedimentation of petroleum dispersed systems in the presence of additives containing amino and phosphate groups. Proceedings of the National Academy of Sciences of Belarus, 2017, vol. 1, pp. 99-108. In Rus.

7. Nefedov N.I., Semenova L.V., Kuznetsova V.A., Vereninova N.P. Paint and varnish coatings for the protection of metal and polymer composite materials from aging, corrosion and bio-damage. Aviation materials and technologies, 2019, vol. 5, pp. 62-67. In Rus.

8. Zhu W., Dong X., Huang H., Qi M. Iron nanoparticles-based magnetorheological fluids: a balance between MR effect and sedimentation stability. Journal of Magnetism and Magnetic Materials, 2019, vol. 491, pp. 165556.

9. Summ B.D., Goryunov Yu.V. Fiziko-khimicheskie osnovy smachivaniya $i$ rastekaniya [Physico-chemical bases of wetting and spreading]. Moscow, Khimiya Publ., 1976. 232 p.

10. Tolstaya S.N., Shabanova S.A. Primenenie poverkhnostnoaktivnykh veshchestv $v$ lakokrasochnoy promyshlennosti [Application of surface-active substances in the paint and varnish industry]. Moscow, Khimiya Publ., 1979. $176 \mathrm{p}$

11. Davis R.H., Birdsel JKH. Hindered settling of semidilute monodisperse and polydisperse suspensions. AIChE JournaI, 1988, vol. 34, pp. 123-129.

12. Shaikh K.J., Osio V.A., Leeflang M.M., Shaikh N. Procalcitonin, C-reactive protein, and erythrocyte sedimentation rate for the diagnosis of acute pyelonephritis in children. Cochrane Database of Systematic Reviews, 2020, vol. 1, pp. CD009185.

13. Patwardhan V.S., Chi Tien. Sedimentation and liquid fluidization of solid particles of different sizes and densities. Chemical Engineering Science, 1985, vol. 40, pp. 1051-1060. 
14. Chen Z., Liu J., Chen C., Huang Z. Sedimentation of nanoplastics from water with $\mathrm{Ca} / \mathrm{Al}$ dual flocculants: Characterization, interface reaction, effects of $\mathrm{pH}$ and ion ratios. Chemosphere, 2020, vol. 252, pp. 126450.

15. Bolatbaev K.N., Dyuryagina A.N., Ostrovnoy K.A. Sposob polucheniya ingibitora kislotnoy korrozii metallov [Method for producing an inhibitor of acid corrosion of metals]. Patent RK, no. 22296, 2010.

16. Barfod N. Concentration dependence of sedimentation rate of particles in dilute suspensions. Z Powder Technology, 1972, no. 6, pp. 39-43.

17. Passowa U., Stout S.A. Character and sedimentation of «lingering» Macondo oil to the deep-sea after the Deepwater Horizon oil spill. Marine Chemistry, 2020, vol. 6, pp. 39-43.

18. Dyuryagina A.N. Modification of composites by surfactants. Petropavlovsk, NKZU, 2020.183 p.

19. Dyuryagina A.N., Tukachev A.A., Bolatbaev K.N., Lugovitskaya T.N. Kompyuterno-mikroopticheskiy kompleks dlya kachestvenno-kolichestvennoy otsenki kachestva poverkhnosti izdeliy [Computer-micro-optical complex for qualitative and quantitative assessment of the surface quality of products]. Certificate RK, no. 0806PK0079, 2006.

20. Dyuryagina A.N., Byzova Yu.S., Ostrovnoy K.A., Kondratov A.A., Lukmanova A.M Osobennosti vliyaniya sintezirovannogo modifikatora AS na regulirovanie mezhfaznykh protsessov v sisteme «pigment-rastvoritel» [Features of the influence of the synthesized AC modifier on the regulation of interphase processes in the «pigment-solvent» system]. Materialy II mezhdunarodnoy practicheskoy konferentsii. Aktualniye problemi nauki i obrazovaniya $v$ oblasti estestvennykh i selskokhozyaistvennykh nauk [Materials of the II International scientific and Practical Conference. Actual problems of science and education in the field of natural and agricultural sciences]. Petropavlovsk, North Kazakhstan State University Publ., 2014. pp. 142-147.

Received: 1 December 2021.

\section{Information about the authors}

Antonina N. Dyuryagina, Cand. Sc., associate professor, head of the Chemistry and chemical technologies Department, NC JSC North Kazakhstan University named after M. Kozybayev.

Kirill A. Ostrovnoy, senior lecturer, NC JSC North Kazakhstan University named after M. Kozybayev.

Daria Yu. Kozik, student, NC JSC North Kazakhstan University named after M. Kozybayev. 